九州大学学術情報リポジトリ

Kyushu University Institutional Repository

\title{
Analysis of Landslide Risk Area Susceptibility Using GIS : a Case Study of Injegun, Gangwondo, South Korea
}

Jun, Kye-Won

Graduate School of Disaster Prevention, Gangwon National University

Oh, Chae-Yeon

Disaster Prevention \& Safety Engineering, Gangwon National University

Lee, Si-Young

Graduate School of Disaster Prevention, Gangwon National University

Park, Gwan-Soo

Department of Forest Resources, Chungnam National University

他

https://doi.org/10.5109/1526295

出版情報：九州大学大学院農学研究院紀要. 60 (1)，pp.43-50，2015-02-27. Faculty of Agriculture， Kyushu University

バージョン :

権利関係 : 


\title{
Analysis of Landslide Risk Area Susceptibility Using GIS: a Case Study of Injegun, Gangwondo, South Korea
}

\author{
Kye-Won JUN ${ }^{1}$, Chae-Yeon $\mathrm{OH}^{2}$, Si-Young LEE ${ }^{3}$, \\ Gwan-Soo PARK ${ }^{4}$ and Shoji OHGA*
}

\author{
Laboratory of Forest Resources Management, Division of Forest Environmental Sciences, \\ Department of Agro-Environmental Sciences, Faculty of Agriculture, Kyushu \\ University, Fukuoka 811-2415, Japan \\ (Received October 24, 2014 and accepted November 14, 2014)
}

\begin{abstract}
Extreme climate phenomena are occurring around the world caused by global climate change, and Korea is no exception. Heavy rains continue to occur in Korea, which exceed the previous highest rainfall records. In particular, as flash floods generate heavy rainfall on the mountains over a relatively a short period of time, the likelihood of landslides increases. Therefore, it is necessary to scientifically analyze landslide risk areas to minimize damage in the event of a landslide, and to collect and analyze a variety of spatial information. This study constructs a spatial information database using GIS and integrating geography, hydrology, geology, and forestry, which is required for a complete analysis of landslide risk areas. We also carried out a case study of Injegun, Gangwondo, which suffered from serious landslides and flash floods in 2006 after Typhoon Ewiniar, by overlaying site monitoring data with airborne images.

Furthermore, this study evaluates slope stability of the affected areas using SINMAP (Stability Index Mapping), analyzes spatial data that have high correlation with selected landslide areas using Likelihood Ratio, and prepares landslide prediction of the mountainous areas that are vulnerable to disasters.
\end{abstract}

Key words: Landslide, GIS, SINMAP, Likelihood Ratio

\section{INTRODUCTION}

Up to $64 \%$ of the Korean territory is covered by forest. There are many steep slope areas with $30-60^{\circ}$ tilt angles, and $90 \%$ of the mountainous areas consist of granite and metamorphic rocks. Many landslides occur in Korea each year due to climatic, geographical, geological, and human-induced reasons. In Gangwondo, 81\% of the area consists of mountains and most of the mountain sides have steep slopes. As a result, this area suffers annually from many landslides. For example, heavy rains and Typhoon Ewiniar in July, 2006 caused many landslides throughout Gangwondo. In Injegun (the mountainous area accounting for $90 \%$ of the total area), heavy rains, which fell over a short period of time, caused serious damage to small- and medium-sized streams that had narrow drainage areas. During this flash flood, 29 residents were killed or went missing, and many properties were damaged (Yoo and Choi, 2011). In July, 2011, the Mt. Umyeon landslide occurred in the center of Seoul Metropolitan City (Jun and Oh, 2011). Furthermore, a landslide from a mountain near the residential area of the Chuncheon holiday destination caused loss of life

1 Graduate School of Disaster Prevention, Gangwon National University, 346 Joongang-ro, Samcheok, Gangwon, 245-711, Republic of Korea

2 Disaster Prevention \& Safety Engineering, Gangwon National University, 346 Joongang-ro, Samcheok, Gangwon, 245-711, Republic of Korea

${ }^{3}$ Graduate School of Disaster Prevention, Gangwon National University, 346 Joongang-ro, Samcheok, Gangwon, 245-711, Republic of Korea

${ }^{4}$ Department of Forest Resources, Chungnam National University, Daejeon-Si 305-764, Republic of Korea

* Corresponding author (E-mail: ohga@forest.kyushu-u.ac.jp) and damage to properties. Considering this recent trend, it is clear that many landslides are regularly generated by typhoons or heavy rain and, accordingly, the damage caused is increasing. Therefore, it is necessary to scientifically analyze and systematically manage high landslide risk areas to effectively respond to the incidents. In addition, it is also necessary to investigate the causes of landslides and perform integrated analysis of high risk areas with historical evidence of past natural disasters. Recently, much research has been performed using GIS and remote sensing methods, together with spatial information databases integrating geography, hydrology, geology, and forestry to identify characteristics and causes of landslides. The Korea Forest Research Institute and the Korea Forest Service have developed and implemented the 'Landslide Risk Areas Management System' to prevent and manage landslides in a scientific way. The Korea Institute of Geoscience and Mineral Resources has also prepared a landslide prediction map (Chae and Cho, 2008). At present, there is a need for practical research based on this map to predict landslides more precisely and reduce the number of casualties of landslides.

The infinite slope stability model has been the most common method to evaluate slope stability and landslide risk using GIS technology, where the level of slope stability is defined based on slope angles and the catchment basin (Montgomery and Dietrich, 1994). A more sophisticated model integrating the infinite slope stability model with the dynamic modeling of hydrology has also been proposed (Wu and Sidle, 1995). A further method is SINMAP, used to analyze slope stability, which was developed by combining the infinite slope stability model and numerical modeling (Pack et al., 1998).

Landslide susceptibility evaluation and prediction 
have been established using GIS and RS methods (Kim et al., 2005). For example, a study on highway avalanches was performed to estimate the locations and number of avalanches using SINMAP (Jang et al., 2008). The Korea Forest Research Institute conducted a research to develop a method that can predict occurrence characteristics of avalanches and scale of damage (Oh et al., 2006). The institute carried out a landslide case study using the SINMAP method and showed that it could be an effective tool in preliminary estimates of landslide risk in mountainous areas with steep slopes and thin soil layers. Furthermore, it is expected that this method can be applied effectively to identify high risk landslide areas with a hydrological interpretation of SINMAP, which was used to analyze the Mt. Umyeon landslide that occurred in 2011. In addition, the institute conducted risk analysis of basins affected by avalanches using GIS and to do this, it applied a statistical method consisting of SINMAP and seven parameters (angle of slope, country rock, condition of forest, length of slope, position of slope, shape of slope, and depth of soil) (Jun et al., 2011).

Many landslide susceptibility analyses using GIS include probabilistic, statistical and artificial neural network analyses. The Likelihood Ratio based on Bayesian analysis can quantitatively emphasize an area vulnerable to landslides by calculating the likelihood ratio between landslide affected and other areas (Chung and Fabbri, 1998). To test the validity of the results, several probabilistic methods are usually compared using landslide occurrence positions of two groups that are temporally separated from each other (Chung and Fabbri, 1999). A study modeled landslide susceptibility of Colorado, USA using the weight of evidence technique (Regmi et al., 2010). Another study conducted research on landslide susceptibility using the entropy of the latest GIS (Pourghasemi et al., 2012), while in the conditional probabilistic model index is used to compare and evaluate landslide maps using three methods: frequency ratio, weights of evidence and logistic regression (Ozdemir and Altural, 2013).

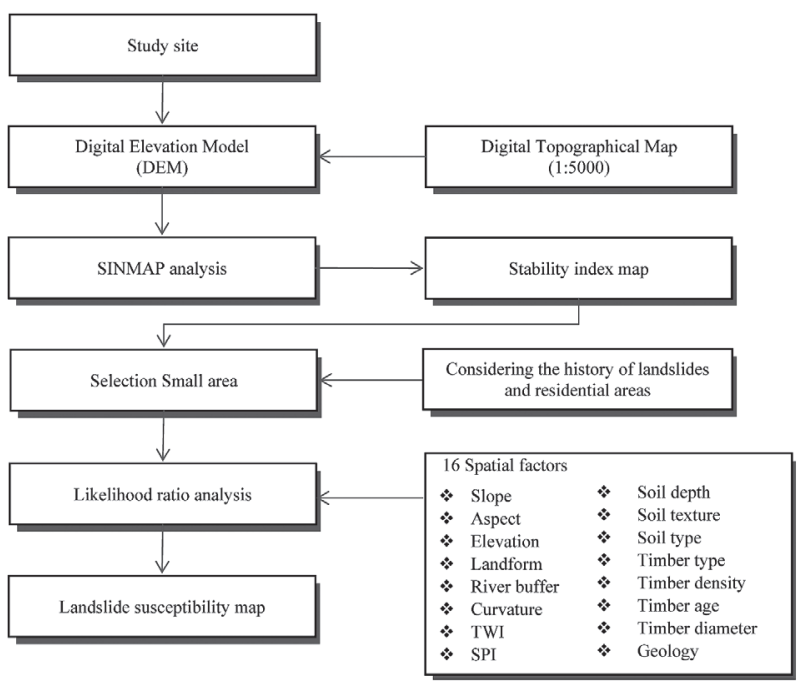

Fig. 1. Flow chart of the work methodology.
In this study, we construct a database of different geographic-spatial information in the GIS environment to evaluate landslide susceptibility and to find potential risk areas by applying the GIS based SINMAP and Likelihood Ratio methods. We also carried out slope stability analysis using SINMAP (the deterministic method) to identify its correlation to occurrence of landslides, analyzed the relationship between landslide and other geographical spatial features by applying the Likelihood Ratio (the probabilistic method), and drew cartography of the disaster to reflect landslide susceptibility. The methodology is shown in (Figure 1).

\section{METHODS}

\section{The SINMAP method}

The SINMAP methodology is based on the infiniteslope stability model (Hammond et al., 1992) that balances (with edge effects neglected) destabilizing components of gravity against stabilizing components of friction and cohesion on a failure plane parallel to the ground surface. Based on the infinite-slope form of the MohrCoulomb failure law, as expressed by the ratio of stabilizing forces (shear strength) to destabilizing forces (shear stress) on a failure plane parallel to the surface, the safety factor calculation in SINMAP is

$$
F S=\frac{C_{r}+C_{s}+\cos ^{2} \theta\left[\rho_{s} g\left(D-D_{w}\right)+\left(\rho_{s} g-\rho_{u} g\right) D_{w}\right] \tan \phi}{D \rho_{s} g \sin \theta \cos \theta}
$$
equation 1

where, $C_{r}$ is the root cohesion $\left(\mathrm{N} / \mathrm{m}^{2}\right), C_{s}$ is the soil cohesion $\left(\mathrm{N} / \mathrm{m}^{2}\right), \theta$ is the slope angle $\left({ }^{\circ}\right), \rho_{s}$ is wet soil density $\left(\mathrm{kg} / \mathrm{m}^{3}\right), \rho_{w}$ is the density of water $\left(\mathrm{kg} / \mathrm{m}^{3}\right), \mathrm{g}$ is gravitational acceleration $\left(9.81 \mathrm{~m} / \mathrm{s}^{2}\right), D$ the vertical soil depth $(\mathrm{m}), D_{w}$ the vertical height of the water table within the soil layer $(\mathrm{m})$, and $\phi$ the internal friction angle of the soil $\left(^{\circ}\right)$. The slope angle, $\theta$, is the arc tangent of the slope, $S$, expressed as a decimal drop per unit horizontal distance. Figure 2 illustrates the geometry assumed in equation (1). Soil thickness, $h(\mathrm{~m})$, and depth, $D$, are related by $h=D \cos \theta$. With this change FS reduces to

$$
F S=\frac{C+\cos \theta[1-w r] \tan \phi}{\sin \theta} \ldots \ldots \ldots \ldots \ldots \ldots \ldots \text { equation } 2
$$

$\mathrm{C}, \mathrm{w}$, and $\mathrm{r}$ denote the dimensionless cohesion, wetness

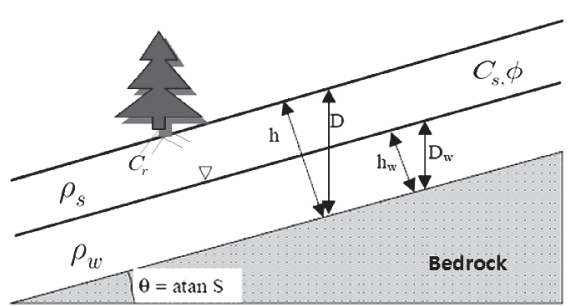

Fig. 2. The geometry of the assumed infinite slope stability model and parameters involved in the safety factor 
index, and density ratio, respectively, and are defined in the context of SINMAP as shown below

$$
\begin{aligned}
& \mathrm{C}=\frac{\left(C_{r}+C_{s}\right)}{\left(h \rho_{s} g\right)} \\
& \mathrm{w}=\frac{D_{w}}{D}=\operatorname{Min}\left(\frac{R a}{\mathrm{~T} \sin \theta}, 1\right) \\
& \mathrm{r}=\frac{\rho_{w}}{\rho_{s}}
\end{aligned}
$$

The term $R$ which appears in the wetness index equation, equation (3), is the effective recharge, Term a which also appears in the same equation stands for the specific catchment area defined as the upslope area per unit contour length with units $\mathrm{m}^{2} / \mathrm{m}$. As shown in Figure $2 h$ is the depth to the plane of failure measured in a direction perpendicular to the ground surface, and r, as defined by equation (5), is water to saturated soil density ratio. The complete description of SINMAP model for a particular region of interest requires 2 variables and 3 parameters, as follows:

Variables: $\theta$ and $\alpha$

Parameters: $C, \phi$, and the ration $R / T$

The variables are implicitly inputted in the form of a digital elevation model, DEM, for the model to calculate them from inbuilt modules for each and every pixel. An inventory of landslide initiation points is utilized for validating the model output (Fowze et al., 2012). SINMAP holds the soil density ratio constant and allows variability in the soil cohesion, internal friction angle, and R/T using a uniform probability distribution given a specified lower and upper limit. SINMAP expresses the terrain stability by six broad classes with subjective breakpoints (Table 1).

\section{The Likelihood Ratio method}

The Likelihood Ratio is a data-driven method that is basically the Bayesian approach in a log-linear form using the prior and posterior probability, and is applied where sufficient data are available to estimate the relative importance of evidential themes by probability means.

In the Bayesian approach, sureness measures obey the basic axioms of probability theory and the basic expressions are statements about the prior, likelihood and posterior probabilities.

One of main concepts for applications is that the prior probability is successively updated with the addition of new evidence, so that the posterior probability from adding one piece of evidence can be treated as the prior probability for adding a new piece of evidence.

For a given number of units cells, $\mathrm{N}\{D\}$, containing an occurrence, $D$, and the total number of unit cell in the study area, $N\{T\}$, the prior probability of an occurrence is expressed by

$$
P\{D\}=\frac{N\{D\}}{N\{T\}}
$$
equation 6

Supposing that a binary predictor pattern, B, occupying $\mathrm{N}\{F\}$ unit cells, occurs in the region, and that a number of known landslides occurs preferentially within the pattern, i.e., $N\{D \mid F\}$, then the favorability of locating an occurrence, given the presence of a predictor and the absence of a pattern, can be expressed by the conditional probabilities.

$$
\begin{aligned}
& \mathrm{P}\{D \mid F\}=\frac{P\{D \cap F\}}{P\{F\}}=P\{D\} \frac{P\{F \mid D\}}{P\{F\}} \text {....equation } 7 \\
& \mathrm{P}\{D \mid \bar{F}\}=\frac{P\{D \cap \bar{F}\}}{P\{\bar{F}\}}=P\{D\} \frac{P\{\bar{F} \mid D\}}{P\{\bar{F}\}} \text {....equation } 8
\end{aligned}
$$

\begin{tabular}{|c|c|c|c|c|}
\hline Condition & Class & Predicted state & Parameter range & $\begin{array}{l}\text { Passible influence of factors not } \\
\text { modeled }\end{array}$ \\
\hline $\mathrm{SI}>1.5$ & 1 & Stable slope zone & Range cannot model instability & $\begin{array}{l}\text { Significant destabilizing factors are } \\
\text { required for instability }\end{array}$ \\
\hline $1.5>\mathrm{SI}>1.25$ & 2 & Moderately stable slope zone & Range cannot model instability & $\begin{array}{l}\text { Moderate destabilizing factors are } \\
\text { required for instability }\end{array}$ \\
\hline $1.25>\mathrm{SI}>1.0$ & 3 & Quasi-stable slope zone & Range cannot model instability & $\begin{array}{l}\text { Minor destabilizing factors could } \\
\text { lead to instability }\end{array}$ \\
\hline $1.0>\mathrm{SI}>0.5$ & 4 & Lower threshold slope & $\begin{array}{l}\text { Pessimistic half of range required } \\
\text { for instability }\end{array}$ & $\begin{array}{l}\text { Destabilizing factors are not } \\
\text { required for instability }\end{array}$ \\
\hline $0.5>\mathrm{SI}>0.0$ & 5 & Upper threshold slope & $\begin{array}{l}\text { Optimistic half of range required } \\
\text { for stability }\end{array}$ & $\begin{array}{l}\text { Stabilizing factors may be } \\
\text { responsible for stability }\end{array}$ \\
\hline $0.0>\mathrm{SI}$ & 6 & Defended slope zone & Range cannot model instability & $\begin{array}{l}\text { Stabilizing factors are required for } \\
\text { stability }\end{array}$ \\
\hline
\end{tabular}

The posterior probability of an occurrence given the presence and absence of the predictor pattern are

Table 1. Classes of slope stability based on values of the Stability Index (SI) 
denoted by $P\{D \mid F\}$ and $P\{D \mid \bar{F}\}$, respectively; $P\{D \mid F\}$ and $P\{\bar{F} \mid D\}$ are the posterior probabilities of being inside and outside the predictor pattern, F, respectively, given the presence of an occurrence, D. Furthermore, $P\{F\}$ and $P\{\bar{F}\}$ are the prior probabilities of being inside and outside the predictor pattern, respectively. The same model can be expressed in an odds-type formulation, where the odds, $O$, are defined as $O=P /(1-P)$. Expressed as odds, equation (7) and (8), respectively, become

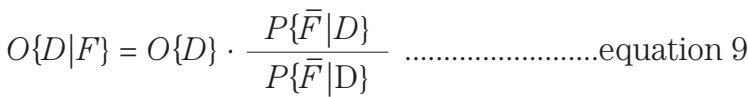

$$
\begin{aligned}
& \mathrm{O}\{D \mid \bar{F}\}=O\{D\} \cdot \frac{P\{F \mid D\}}{P\{F \mid \bar{D}\}}
\end{aligned}
$$

where $O\{D \mid F\}$ and $\mathrm{O}\{D \mid \bar{F}\}$ are the posterior odds of an occurrence given the presence and absence of a binary predictor pattern, respectively, and $O\{D\}$ is the prior odds of an occurrence.

\section{THE STUDY AREA}

We selected Injegun and the surrounding area of Gangwondo as the study area for landslide analysis (Figure 3). Landslide occurrence points were drawn from overlay analysis of airborne pictures taken before and after landslides in 2005 and 2006, and from site monitoring activities. In 2006, many landslides occurred in this area due to Typhoon Ewiniar and heavy rains. The total rainfall for this region for July 12-16, 2006 was 569.6mm. The highest recorded amount of rainfall during this period was $192 \mathrm{~mm}$ on July 15, and $65.5 \mathrm{~mm}$ was recorded as the highest hourly rainfall. As landslides have different patterns and occurrence frequencies, it is difficult to select a standard quantitative value for each landslide factor. Therefore, it is necessary to analyze the spatial correlation between landslide occurrence positions and each landslide factor using GIS once the landslide factors have been selected.

\section{RESULTS AND DISCUSSION}

\section{Application of the SINMAP model}

This study identifies the levels of slope stability for landslide occurrence in the target area using SINMAP. This method is used to evaluate the moment of stability by applying inducing factors (such as geographical features, quality of soil, and climate) to a hydrological or a slope stability model including geography, and using a deterministic method that is based on physics and dynamics. Based on our findings (Figure 4), the area of $\mathrm{SI}<0.5$ and $1.0<\mathrm{SI}<0.5$ was $17.5 \mathrm{~km}^{2}$ and $109 \mathrm{~km}^{2}$, respectively. In other words, $44 \%$ of the total forest area $\left(285 \mathrm{~km}^{2}\right)$ can be classified as landslide risk area. Conversely, approximately $25 \%\left(72 \mathrm{~km}^{2}\right)$ of the total study area can be regarded as stable area (SI>1.5). The final landslide risk area was estimated with overlay analysis using records of historical landslide occurrence, casualties, and property damage in the area. Table 2 shows the results of SINMAP for the selected basins. Approximately $12 \mathrm{~km}^{2}$, which equals $36 \%$ of the total basin area $\left(33.64 \mathrm{~km}^{2}\right)$, can be included in the risk area.

\section{Application of the Likelihood Ratio model}

The likelihood ratio, which is obtained on the basis of conditional probabilities, is equal to the ratio of the landslide area by the level of each factor. If the likelihood ratio is 1 , the probability of landslide occurrence is the average compared with other landslide inducing factors. If the ratio is greater than 1 , the probability of landslide occurrence is relatively high. If the ratio is less

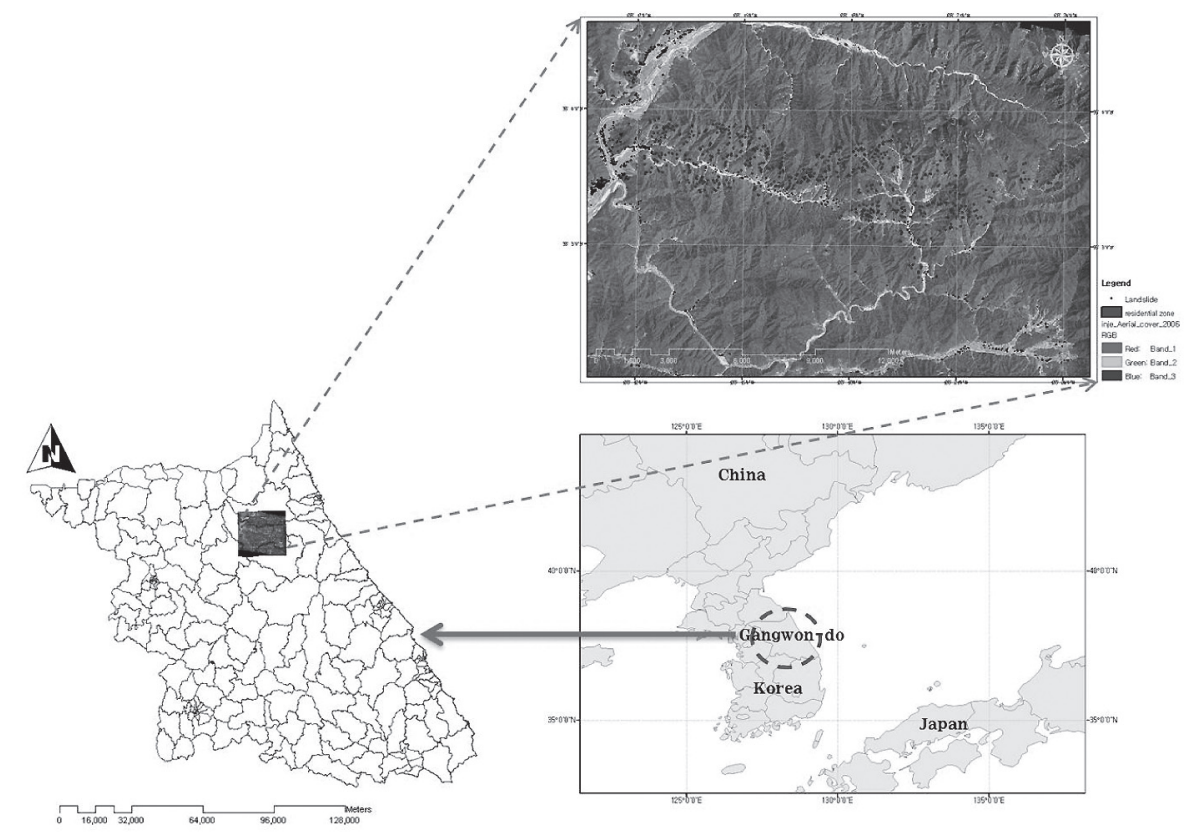

Fig. 3. Study area and an aerial image map of landslides (2006). 
Table 2. Classes of slope stability based on value of the Stability Index (SI)

\begin{tabular}{|c|c|c|c|c|c|c|c|}
\hline & $\begin{array}{l}\text { Stable } \\
\text { (S) }\end{array}$ & $\begin{array}{c}\text { Moderately } \\
\text { Stable } \\
\text { (MS) }\end{array}$ & $\begin{array}{c}\text { Quasi- } \\
\text { Stable } \\
\text { (QS) }\end{array}$ & $\begin{array}{cc}\text { is } & \text { Lower } \\
\text { ingeshold } \\
\text { Th) }\end{array}$ & $\begin{array}{c}\text { Upper } \\
\text { Threshold } \\
\text { (UT) }\end{array}$ & $\begin{array}{l}\text { Defended } \\
\text { (D) }\end{array}$ & I Total \\
\hline $\begin{array}{l}\text { Area } \\
\left(\mathrm{km}^{2}\right)\end{array}$ & 10.0 & 4.7 & 7.0 & i & 0.9 & 0.04 & I 33.64 \\
\hline $\begin{array}{c}\% \text { of } \\
\text { Region }\end{array}$ & 30 & 14 & 21 & i & 3 & 0 & $\begin{array}{ll}\mathbf{I} & 100 \\
\mathbf{I} & \end{array}$ \\
\hline
\end{tabular}

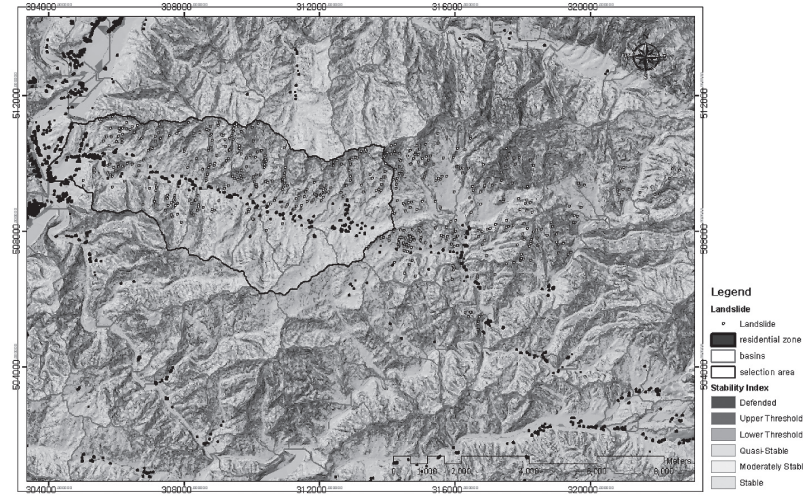

Fig. 4. Stability index map.

than 1 , the probability of landslide occurrence is relatively low. To identify the characteristics of landslide occurrence locations, the factors are classified into appropriate groups to ensure that the attributes of each factor reflect its original value well. Using this process, the number of landslides that occurred in each class can be statistically identified.

We produced a database to perform likelihood ratio analysis on basin areas selected in the SINMAP analysis.
This method also configures points, lines, faces, and coordinates, which are attributes of each factor required to prepare prediction, and builds 16 types of spatial databases, including geography, hydrology, geology, forestry, and geology (Figure 5).

For the relationship between landslide and geographical factors, the likelihood ratio of a slope of greater than $25^{\circ}$ (Figure 6(a)) is more than 1, which shows that the probability of landslide occurrence is significantly increased. For the slope aspect (Figure 6(b)), the probability of landslide occurrence was high in the East and Southeast, and very high in the South with a probability of 3.11. For altitude (Figure 6(c)), the highest probability of landslide occurrence was found between 500-600 m, measuring 1.49. Landform (Figure 6(d)) was divided into 10 levels from flat ground, and ridge to the top of a mountain. According to the results, the likelihood ratio of a deep and a flat valley were 1.61 and 1.37, respectively. For curvature (Figure 6(e)), the negative value means that the slope plane is concave, while a positive value indicates that the slope plane is convex. Zero (0) shows that the slope plane is flat. The value of curvature is correlated to the convex area with 1.26.

Hydrological factors were analyzed using a buffer
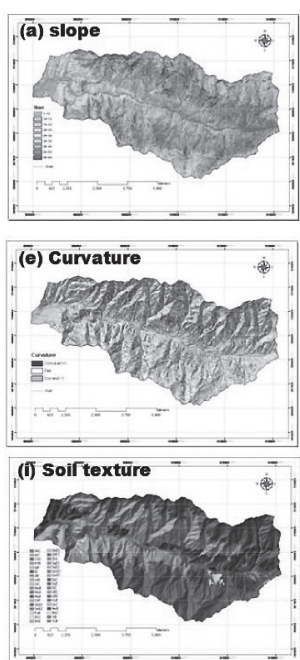

(i) Timber densīty -

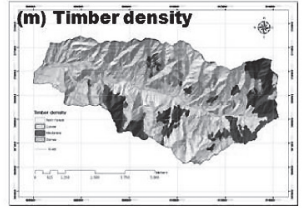

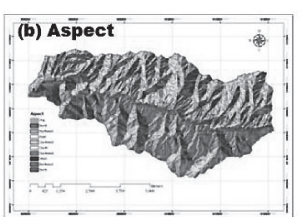
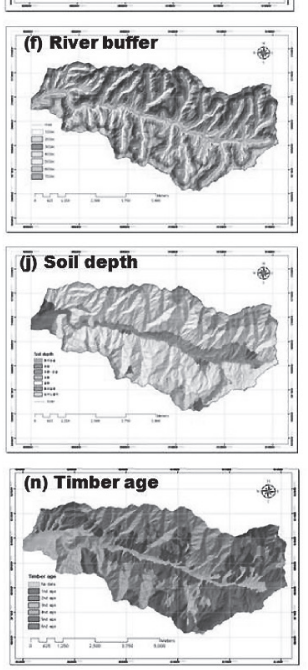
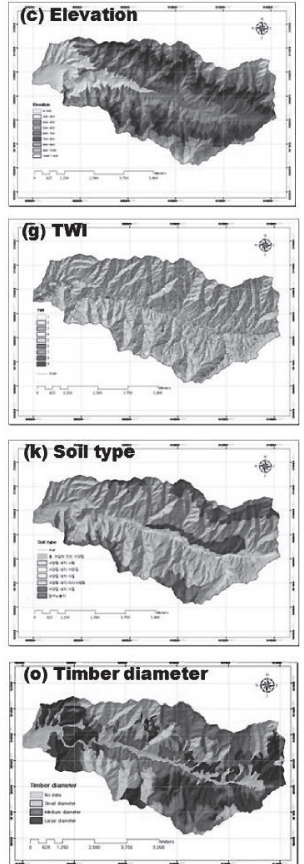
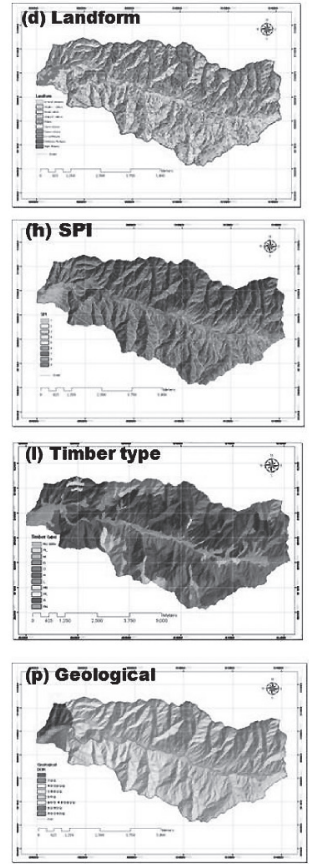

Fig. 5. Maps in the spatial database used for landslide susceptibility analysis. 


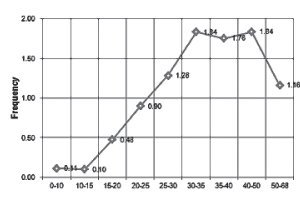

(a) Slope

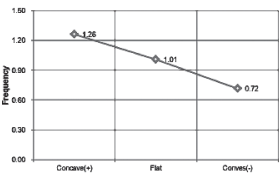

(e) Curvature

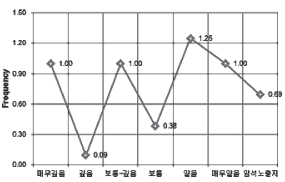

(i) Soil texture

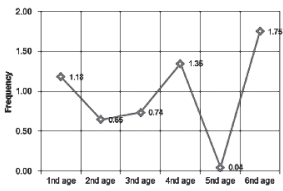

(m) Timber density

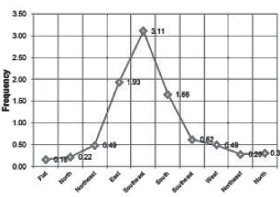

(b) Aspect

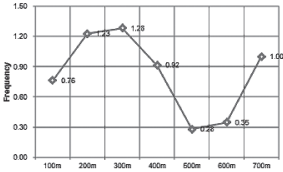

(f) River buffer

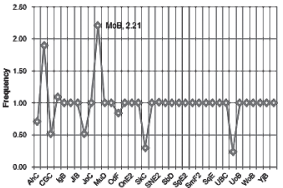

(j) Soil depth

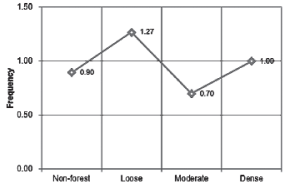

(n) Timber age

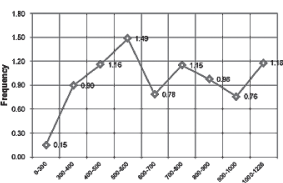

(c) Elevation

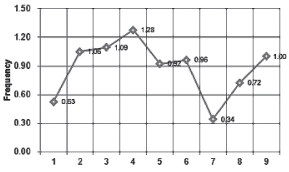

(g) TWI

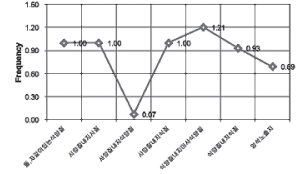

(k) Soil type

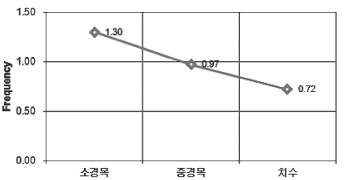

(o) Timber diameter

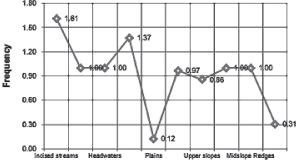

(d) Landform

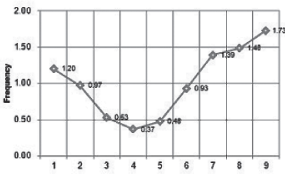

(h) SPI

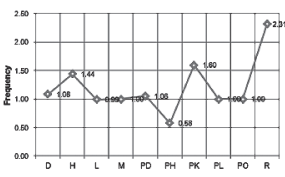

(1) Timber type

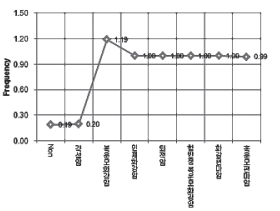

(p) Geological

Fig. 6. Likelihood ratio between Mountainous disaster and related Factor.

zone, which was $100 \mathrm{~m}$ in length along a river, to measure correlation between basin areas and landslide occurrence positions, as shown in Figure 6(f). According to the results of the likelihood ratio, the values for $200 \mathrm{~m}$ and $300 \mathrm{~m}$ were 1.23 and 1.28 , respectively. In fact, $90 \%$ of the landslide occurrence positions in the target area were located within $300 \mathrm{~m}$ of the river. Values for the TWI (Topographic Wetness Index) factor from 0 to 23.7 are divided into nine levels, which are in inverse proportion to the values of the slope. According to the results, level 4 had the highest probability value with 1.28. As seen in Figure 6(g), it has a negative relationship with landslide occurrence, unlike the slope. SPI (Stream power Index) (Figure 6(h)), a factor indicating the area of sloped basin, was analyzed with nine subgroups between 4.12 and -4.37 . Classes 8 and 9 , which have a high SPI value, had probabilities of 1.48 and 1.73 , respectively.

Soil was analyzed by a code (Figure 6(i)) using a detailed soil map. The highest likelihood ratio was found in the Soil Code Mob with 2.21. Soil depth (Figure 6(j)) consists of categories of 'Very Deep', 'Deep', 'Moderate', 'Thin', 'Very Thin', and 'Rock Exposed'. The highest likelihood ratio, of 1.25, was found in the 'Thin' area. For the soil types, clay loam or silt clay loam has a probability of 1.21

The relationship between forestry factors, including Timber type, Timber density, Timber age, and Timber diameter, was identified. For Timber type (Figure 6(1)), the non-forest area (R) had the highest value (2.31). Deciduous and Pinus koraiensis forests also had a high probability (1.44 and 1.60, respectively). For Timber density (Figure 6(m)), the low density area had higher probability of landslides occurrence than the high density area. Timber had high correlation at age four and six years of 1.35 and 1.75, respectively (Figure 6(n)). For Timber diameter (Figure 6(o)), the timber with a small diameter had a 1.30 probability. For the geological features, a 1.19 probability value was found for Two-Mica Granite (Figure 6(p)).

Landslides Susceptibility Index by likelihood ratio (LR) was calculated from an overlay analysis, as shown in equation (11), which was calculated by allocating a likelihood ratio to a class of each factor. Figure 7 shows the predictions of landslide risk areas that are constructed by overlapping areas with high correlation. The Landslides Susceptibility Index areas are classified into $5 \%, 10 \%, 15 \%$, and $70 \%$ to indicate risk levels of Very high, High, Medium, and Low.

$$
L S I_{L R}=L R_{1}+L R_{2}+L R_{3}+\ldots+L R_{n} \text {.....equation } 11
$$

where $L R_{n}$ is the likelihood ratio of each factor type or range.

The prediction rate curve (Figure 8) illustrates how well the estimators perform with respect to the landslides used in constructing the estimators [20]. The range was classified by area, which was equal to approximately $5 \%$. The prediction rate measures how well the model predicts the distribution of future landslides. To calculate the prediction rate, we first counted the number of pixels of validated landslides in the landslide hazard level 
whose value is greater than (100 minus a specific value) $\%$. The percentage was then divided by the total number of pixels of validated landslides to obtain a normalized prediction rate. The prediction rate curve is the cumulative version of the prediction rate. It has the form $\mathrm{y}=$ function $(\mathrm{x})$. Here, $\mathrm{x}$, ranging from 0 to $100 \%$, is the percentage of relative landslide hazard, and corresponds to the legend in the prediction map (Figure 7). The value $y$ is the percentage of occurrences predicted within the most favorable $\mathrm{x}$ of the study area. For example, in the most hazardous top $30 \%$ of areas, the prediction powers of the likelihood ratio were approximately $73 \%$.

\section{CONCLUSIONS}

We applied a GIS based SINMAP model and the Likelihood Ratio to predict landslide risk areas, which can be caused by heavy rains or typhoons in a mountainous area.

We produced maps of landslide occurrence points using the GIS method and airborne images, and constructed a spatial database using geographical, soil, hydrological, and geological factors. We also obtained a slope stable index by applying the SINMAP model to the target area affected by many landslides caused by heavy rains

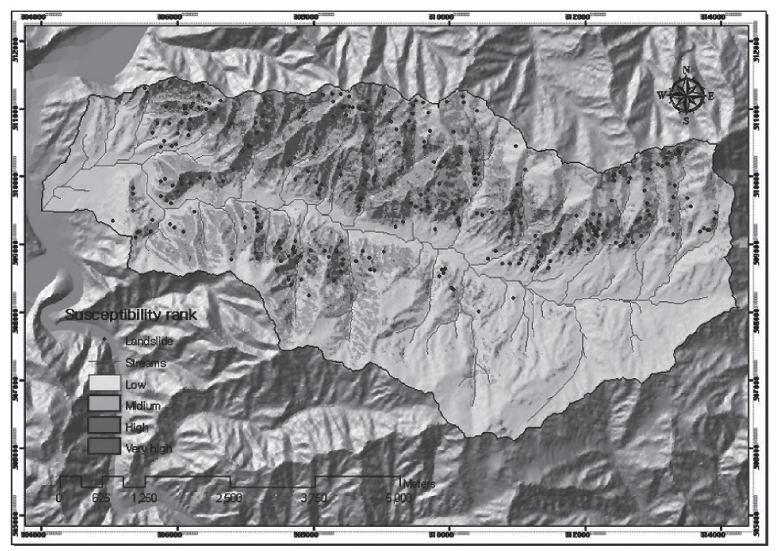

Fig. 7. Landslide susceptibility Index Map based on the Likelihood Ratio.

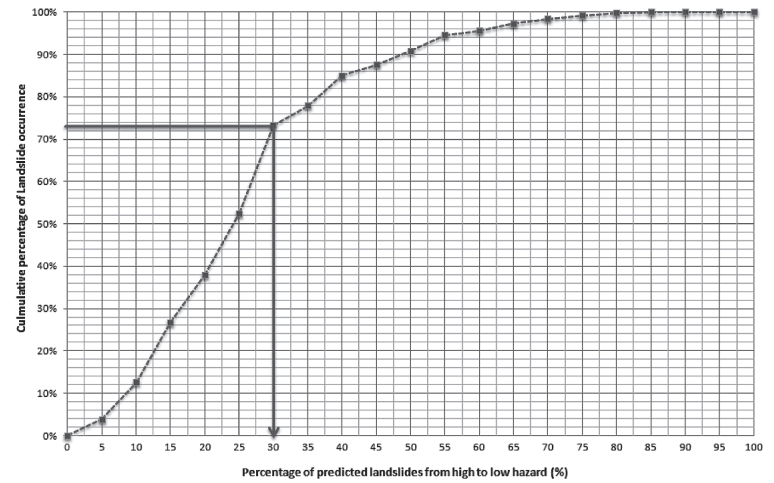

Fig. 8. Illustration of the cumulative frequency diagram showing the Landslides Susceptibility Index rank (x-axis) in cumulative percent of landslide occurrence (y-axis). and Typhoon Ewiniar in 2006, and applied the likelihood ratio model to the basin that had sustained extensive damage in its residential areas. We predicted landslide risk areas and prepared a susceptibility map after conducting overlay analysis of areas with high correlation, which were found using correlation analysis between each factor and landslide occurrence. The Landslides Susceptibility Index is classified into 5\%,10\%, and 15\%, $70 \%$. We show that $73 \%$ of the total points are located in a relatively high risk section (areas classified between Very high and medium, which equal 30\% of the total section). This indicates a relatively high correlation with actual landslide occurrences. We expect that these findings can be effective tools in preparing a risk map of mountain regions or locations close to residential areas.

\section{REFERENCES}

Chung, F. C. and Fabbri, A. G. 1998 Three Bayesian prediction models for landslide hazard. In "Proceedings of International Association for Mathematical Geology 1998 Annual Meeting (IAMG'98)", ed. by A. Bucciantti, Ischia, Italy, pp. 204-211

Chung, F. C. and Fabbri, A. G. 1999 Probabilistic prediction models for landslide hazard mapping. Photogrammetric Engineering and Remote Sensing, 65(12): 1398-1399

Chae, B. G. and Cho, Y. C. 2008 Development of Landslide Prediction Technology and Damage Mitigation Countermeasures. National Emergency management Agency, p. 566

Fowze, J. S. M., Bergado, D. T., Soralump, S., Voottipreux, P. and Dechasakulsom, M. 2012 Rain-triggered landslide hazards and mitigation measures in Thailand: Form research to practice. Geotextiles and Geomembranes, 30: 50-64

Hammond, C., Hall, D., Miller, S. and Swetik, P. 1992 Level I Stability Analysis (LISA) Documentation for Version 2.0. General Technical Report INT-285, US Department of Agriculture, Forest Service, Intermountain Research Station, Ogden, UT, p. 190

Jang, H. I., Kim, K. S. and Lee, S. D. 2008 SINMAP analysis of debris flow in the Youngdong highway. 2008 KSCE Conference, 10: $2972-2975$

Jun, K. W., Oh, C. Y. and Jun, B. Y. 2011 Study on analyzing characteristics which causes a debris flow: focusing on the relation with slope and river. Journal of safety and Crisis Management, 7(3): 223-232

Kim, K. T., Jung, S. G., Park, K. H. and Oh, J. H. 2005 Evaluation of landslide susceptibility using GIS and RS. Journal of the Korean Association of Geographic Information Studies, 8(1): $75-87$

Montgomery, D. R. and Dietrich, W. E. 1994 A physically based model for the topographic control on shallow land sliding. Water Resources Research, 30(4): 1153-1171

Oh, K. D., Hong, I. P., Jun, B. H., Ahn, W. S. and Lee, M. Y. 2006 Evaluation of GIS-based landslide hazard mapping. Journal of Korea Water Resources Association, 39(1): 23-33

Ozdemir, A. and Altural, T. 2013 A comparative study of frequency ratio, weights of evidence and logistic regression methods for landslide susceptibility mapping: Sultan Mountains, SW Turkey. Journal of Asian Earth Sciences, 64: 180-197

Pack, R. T., Tarboton, D. G. and Goodwin, C. N. 1998 Terrain Stability Mapping with SINMAP. Technical Description and User Guide for Version 1.00. Report Number 4114-0, Terra tech Consulting Ltd., Salmon Arm, B. C. Canada

Pourghasemi, H. R., Mohammady, M. and Pradhan, B. 2012 Landslide susceptibility mapping using index of entropy and conditional probability models in GIS: Safarood Basin, Iran Catena, 97: 71-84

Regmi, N. R., Giardino, J. R. and Vitek, J. D. 2010 Modeling sus- 
ceptibility to landslides using the weight of evidence approach: Western Colorado, USA. Geomorphology, 115: 172-187

Jun, K. W. and Oh, C. Y. 2011 Study on analyzing characteristics which causes a debris flow-focusing on the relation with slope and river. Korean Review of Crisis \& Emergency Management, $\mathbf{7}(3)$ : 223-232
Yoo, N. J. and Choi, J. S. 2011 Landslide characteristics for Hoengseong area in 2006. LHI journal of Land, Housing and Urban Affairs, 2(2): 157-162

Wu, W. and Sidle, R. C. 1995 A distributed slope stability model for steep forested watersheds. Water Resources Research, 31(8): 2097-2110 